\title{
Tungsten-Cobalt-Carbon System
}

\author{
by Pekka Rautala and John T. Norton
}

\begin{abstract}
The phases and equilibria in the W-Co-C system have been studied by $\mathrm{X}$-ray diffraction methods, metallographic technique, and thermal analysis. In addition to the $\eta$ phase, two double carbides, called $\theta$ and $\kappa$, have been revealed. The compositions correspond to $\mathrm{Co}_{3} \mathrm{~W}_{6} \mathrm{C}_{2}$ and $\mathrm{Co}_{3}-$ $\mathrm{W}_{10} \mathrm{C}_{\mathrm{t}}$. The reactions leading to these phases have been explained and tentative diagrams of stable and metastable equilibria proposed. The basic reactions in sintering cobalt cemented tungsten carbides are discussed.
\end{abstract}

$\mathrm{T}$ HE W-Co-C system is of fundamental importance in practical carbide manufacturing as well as for the understanding of the sintering mechanism. Surprisingly little is known about this system, for the probable reason that all the important alloys are of two-phase structure and that the diagram Co-WC has been treated as a quasi-binary. This obviously is incorrect, because WC decomposes before melting.

One ternary phase, $\eta$, of composition $\mathrm{Co}_{3} \mathrm{~W}_{3} \mathrm{C}$ has long been known. It was first studied by Adelskold, Sundelin, and Westgren, ${ }^{1}$ although the isomorphous iron-tungsten carbide was known earlier. There have been in the literature several reports of two $\eta$ phases. ${ }^{2,3}$ Also the $\eta$ phase has been considered unstable by Takeda ${ }^{4}$ and Westgren. ${ }^{1}$

The Co-WC diagram has been studied by Wyman and $\mathrm{Kelley}^{\overline{5}}$ and a quasi-binary diagram has been published by Sandford and Trent. ${ }^{2}$ Takeda has published a tentative Co-W-C diagram, considering both metastable and stable equilibria. However, the lines of two-fold saturation are shown only partially and it seems impossible to complete the diagram without violating the phase theory. Therefore it seemed desirable to examine the system in more detail.

\section{Experimental Procedure}

The alloys used in the present investigation were made of powders of tungsten, tungsten monocarbide, cobalt, and carbon and were of the grade used in manufacture of commercial cemented carbides. The powders were ground and mixed in small stainless steel ball mills, using balls of the same material. Benzene was used as a dispersing agent. The mixing period was $1 \mathrm{hr}$, since this was shown to give suffi-

P. RAUTALA is Assistant Professor of Metallurgy and J. T. NORTON, Member AIME, is Professor of Metallurgy, Massachusetts Institute of Technology, Cambridge, Mass.

Discussion on this paper, TP $3360 \mathrm{E}$, may be sent, 2 copies, to AIME by Dec. 1, 1952. Manuscript, April 15, 1952. Philadelphia Meeting, October 1952.

This paper is based on a thesis by P. Rautala submitted in partial fulfillment of requirements for the degree of Doctor of Science in Metallurgy at Mossachusetts Institute of Technology, May 1951. ciently good mixing of the powders without too great a contamination from the mill. After ball milling, the specimens were pressed in cylindrical or rectangular dies. No paraffin or other lubricant was used and the small compacts had sufficient green strength to be handled without difficulty.

Several sintering furnaces were employed. The most satisfactory arrangement was a vacuum furnace based on the Arsem principle which employed a graphite helix as the resistance heating element. Specimens were placed on graphite stands and there was generally a slight carburization or decarburization of the specimen surface, depending on the carbon content of the alloy. The evaporation of the cobalt at a sintering temperature of $1400^{\circ} \mathrm{C}$ was not significant, but became severe at $1500^{\circ} \mathrm{C}$ and higher. The sintering time was $1 \mathrm{hr}$ at $2000^{\circ} \mathrm{C}$ and 2 to $4 \mathrm{hr}$ at lower temperatures. It was not possible to quench the specimens, but the cooling rates were rather fast, greater than $300^{\circ} \mathrm{C}$ in the first minute. In the system under investigation, the reactions are sluggish, and it is believed that the high temperature structures are satisfactorily retained.

The principal method of investigating the sintered specimens was X-ray diffraction by the Norelco recording spectrometer. Approximate determinations of the phase boundaries were made by the disappearing phase method.

\section{Ternary Phases}

To study the phase formation in $\mathrm{W}-\mathrm{Co}-\mathrm{C}$ system, a series of specimens was sintered at $1400^{\circ} \mathrm{C}$. In this experiment two ternary phases, called here $\theta$ and $\kappa$ were formed in addition to the well-known $\eta$ phase. The $\eta$ phase, which has been completely described by Westgren, ${ }^{\circ}$ showed a range of homogeneity from 7 to 20 pct $\mathrm{C}$ and from 38 to 48 pet Co. At $1400^{\circ} \mathrm{C}$ the $\eta$ phase was found to be in equilibrium with monotungsten carbide, $\theta$, tungsten, $\delta, \beta$, and liquid. The boundaries toward $\beta$ and liquid were difficult to determine and appeared to be very temperature sensitive. The other boundaries are believed to be well fixed. The homogeneity range of $\eta$, as measured in this work, is considerably smaller than the one 
Table I. X-Ray Patterns of $\eta, \theta$, and $\kappa$ Phases Planar Spacings $(d)$ and Relative Intensities $(I)$ of Reflections

\begin{tabular}{|c|c|c|}
\hline$h k l$ & $d$ & $I$ \\
\hline \multicolumn{3}{|l|}{$\eta$ Phase } \\
\hline 400 & 2.740 & 0.24 \\
\hline 331 & 2.514 & 0.36 \\
\hline $\begin{array}{l}420 \\
422\end{array}$ & $\begin{array}{l}2.450 \\
2.237\end{array}$ & $\begin{array}{l}0.00 \\
0.65\end{array}$ \\
\hline 511,333 & 2.109 & 1.00 \\
\hline 440 & 1.937 & 0.50 \\
\hline \multicolumn{3}{|l|}{$\theta$ Phase } \\
\hline 400 & 2.813 & 0.09 \\
\hline 331 & 2.581 & 0.41 \\
\hline 420 & 2.516 & 0.00 \\
\hline 422 & 2.296 & 0.51 \\
\hline 511,333 & 2.165 & 1.00 \\
\hline 440 & 1.989 & 0.44 \\
\hline \multicolumn{3}{|l|}{ KPhase } \\
\hline $20.0,10.2$ & 2.299 & 0.10 \\
\hline 20.1 & 3.118 & 0.14 \\
\hline $\begin{array}{l}11.2 \\
00.3\end{array}$ & $\begin{array}{l}2.778 \\
2.620\end{array}$ & $\begin{array}{l}0.00 \\
0.00\end{array}$ \\
\hline $20.2,12.0$ & 2.568 & 0.75 \\
\hline $10.3,21.1$ & 2.447 & 0.80 \\
\hline 30.0 & 2.268 & 0.36 \\
\hline $30.1,11.3$ & 2.179 & 1.00 \\
\hline 21.2 & 2.152 & 1.00 \\
\hline 20.3 & 2.074 & 0.60 \\
\hline $30.2,22.0,00.4$ & 1.962 & 0.40 \\
\hline 22.1 & 1.904 & 0.00 \\
\hline $31.0,10.4$ & 1.886 & 0.10 \\
\hline $31.1,21.3$ & 1.836 & 0.10 \\
\hline $22.2,11.4$ & 1.757 & 0.15 \\
\hline 30.3 & 1.714 & 0.00 \\
\hline $40.0,31.2,20.4$ & 1.702 & 0.35 \\
\hline 40.1 & 1.664 & 0.00 \\
\hline $22.3,00.5$ & 1.570 & 0.00 \\
\hline $40.2,32.0,21.4$ & 1.560 & 0.15 \\
\hline $32.1,31.3,20.5$ & 1.530 & 0.00 \\
\hline $41.0,30.4$ & 1.484 & 0.00 \\
\hline $41.1,11.5$ & 1.459 & \\
\hline 32.2 & 1.451 & 0.00 \\
\hline $40.3,20.5$ & 1.427 & 0.23 \\
\hline $41.2,22.4$ & 1.389 & 0.00 \\
\hline $50.0,31.4$ & 1.351 & 0.25 \\
\hline $50.1,32.3,21.5$ & 1.340 & 0.56 \\
\hline $33.0,00.6$ & 1.308 & 0.35 \\
\hline $41.3,33.1,30.5$ & 1.291 & 0.35 \\
\hline $50.2,42.0,40.2,10.6$ & 1.285 & 0.40 \\
\hline
\end{tabular}

reported by Brownlee. ${ }^{7}$ The two $\eta$ phases, assumed by Sandford and Trent, ${ }^{2}$ are the limiting compositions of $\eta$ saturated by cobalt and tungsten.

The composition of $\theta$ phase corresponds to formula $\mathrm{Co}_{3} \mathrm{~W}_{8} \mathrm{C}_{2}$. It has cubic symmetry and its structure is closely related to the $\eta$ structure. The axial length of the face-centered cubic lattice was measured as 11.25A. The order of the diffraction lines was similar to those of $\eta$, but the relative intensities were slightly different. The characteristic X-ray patterns of $\eta$ and $\theta$ are given in Table I. The composition range of the $\theta$ phase was narrow, about 2 pct. At $1400^{\circ} \mathrm{C}, \theta$ was in equilibrium with monotungsten carbide, $\kappa$, tungsten, and $\eta$, There was a well-defined two-phase field between $\eta$ and $\theta$. A series of specimens, which had their composition in this field, showed a gradual transition of the relative intensities from the $\eta$ to the $\theta$ pattern, without any change in the lattice constants. Fig. 1 shows the $\mathrm{X}$-ray pattern of an alloy in the middle of the two-phase field $\eta+\theta$. There is no mention in the literature of a phase of composition $\mathrm{Co}_{3} \mathrm{~W}_{8} \mathrm{C}_{2}$. However, the phase $\mathrm{Co}_{2} \mathrm{~W}_{4} \mathrm{C}$, proposed by Kisloykova, ${ }^{3}$ has the same $\mathrm{Co}_{0} \mathrm{~W}$ ratio but 4 pct less carbon.

The $\kappa$ phase corresponds to the formula $\mathrm{Co}_{3} \mathrm{~W}_{10} \mathrm{C}_{4}$ Its range of homogeneity was very narrow, less than 1 pct. The lattice was found to be hexagonal and the lattice constants $a$ and $c$ were both equal and measured as $7.848 \AA$. The diffraction lines of the $\kappa$.phase are given in Table $I$ and a typical X-ray pattern is reproduced in Fig. 2. The $\kappa$ phase was found to be

Fig. 1 (top) -X-ray spectrometer pattern of $\eta$ and $\theta$ phases.

Fig. 2 (bottom) -X-ray spectrometer pattern of $\kappa$ phase.
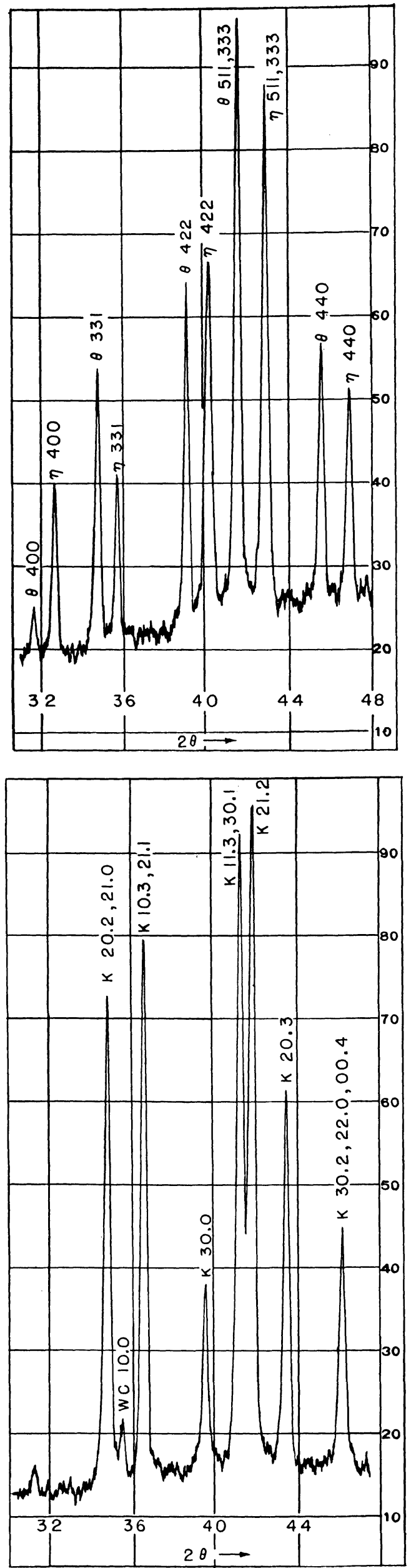
in equilibrium at $1400^{\circ} \mathrm{C}$ with monotungsten and ditungsten carbides, tungsten, and $\theta{ }^{*}$

${ }^{*}$ The $\theta$ and $\kappa$ phases were readily formed in the Fe-W-C and in the Ni-W-C systems with the same compositions and lattices.

\section{Isothermal Section at $1400^{\circ} \mathrm{C}$}

By combining the results of this experiment with $1400^{\circ} \mathrm{C}$ isothermal lines from the adjoining binary diagrams it was possible to construct an isothermal section of W-Co-C diagram. This $1400^{\circ} \mathrm{C}$ isothermal section is illustrated in Fig. 3. The equilibria in the tungsten-rich part of the section have been described in connection with the ternary phases. Of special interest is the two-phase field, WC + liquid, which extends across the isothermal section. After cooling to room temperature, specimens in this field showed a two-phase structure, $\beta+$ WC. Occasionally, depending on the carbon content, $\eta$ or graphite was found in addition. The two-phase field $\beta+\mathrm{WC}$ was very narrow, less than 1 pct in width. The WC phase seems to have a very small solubility for cobalt. All attempts to measure any changes in the lattice constant of WC failed. The boundaries of the liquid phase are known only approximately. This phase extends from the eutectic of the Co-C binary toward the $\eta$ phase.

\section{Ternary Reactions}

The invariant temperatures of the reactions leading to three-phase equilibria $\beta+\mathrm{WC}+$ graphite and $\beta+\eta+\mathrm{WC}$ were determined by thermal analysis. The measurements were made by a modified inverse-rate technique. Alloys in equilibrium with graphite showed a thermal arrest at $1298^{\circ} \mathrm{C}$, whereas alloys in equilibrium with $\eta$ had a thermal arrest at $1357^{\circ} \mathrm{C}$.

To establish the reactions which lead to the formation of the $\eta, \theta$, and $\kappa$ phases, a series of alloys which consisted of one or two of these phases was heated to temperatures of $1700^{\circ}$ and $1880^{\circ} \mathrm{C}$. The specimens were first prepared by sintering at $1400^{\circ} \mathrm{C}$. After rapid cooling from $1700^{\circ} \mathrm{C}$, the $\theta$ and $\kappa$ phases showed no changes, but the specimens containing $\eta$ indicated increasing amounts of $\theta$. The $\eta$ specimens were melted and full of large gas holes, apparently due to evaporation of cobalt. After heating to $1880^{\circ} \mathrm{C}$ both $\theta$ and $\kappa$ showed decomposition. A specimen, originally pure $\theta$, recorded X-ray lines of $\kappa$ and tungsten in addition, whereas a specimen of $\kappa$ composition showed strong lines of $\theta, \kappa$, and $\mathrm{W}_{2} \mathrm{C}$, and weaker lines of tungsten.

These observations suggest the following peritectic reactions:

$$
\begin{aligned}
& \theta=\text { liquid }+\kappa+\mathrm{W} \\
& \kappa=\text { liquid }+\mathrm{W}_{2} \mathrm{C}+\mathrm{W}
\end{aligned}
$$

In the case of $\theta$, the cobalt-rich liquid probably decomposed by evaporation. Traces of $\mathrm{W}_{2} \mathrm{C}$ found in the $\theta$ specimen support this assumption. The liquid from the $\kappa$ decomposition probably solidified under nonequilibrium conditions into $\theta$ and $\kappa$. Because the amount of the liquid, as indicated by the intensities of the $\theta$ lines, was large, the composition of this liquid apparently was not far from the $\kappa$ composition. The small amounts of tungsten found were in accordance with this view.

\section{Tentative Metastable Diagram W-Co-C}

The experimental evidence described permits the construction of a tentative model of the $\mathrm{W}-\mathrm{Co}_{0}-\mathrm{C}$ diagram. It will be shown later that this diagram is of metastable nature. The model is illustrated in Fig.

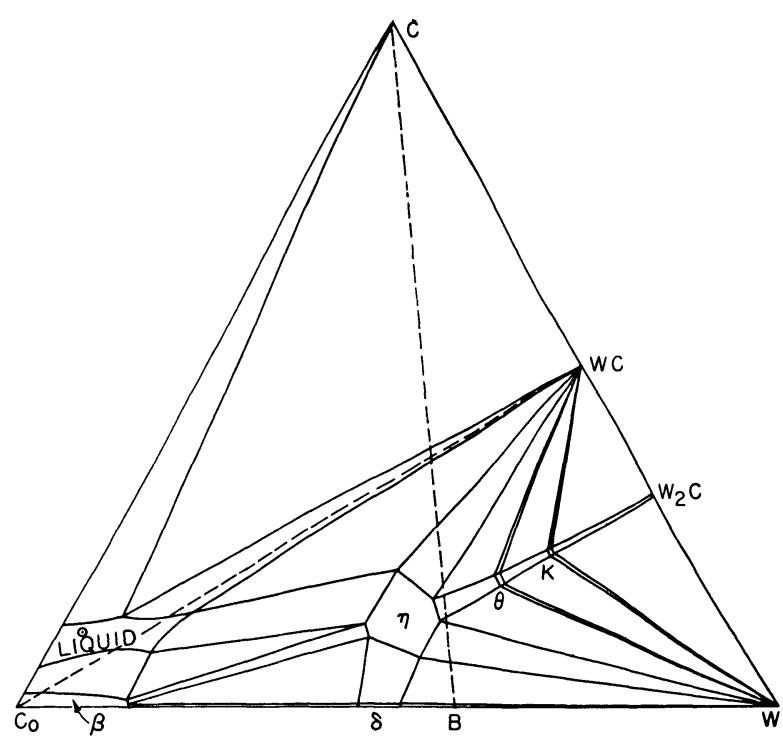

Fig. 3- $1400^{\circ} \mathrm{C}$ isothermal section of W-Co-C equilibrium diagram. The dotted lines $B-C$ and Co-WC correspond to the vertical sections of Figs. 5 and 7.

4, which shows the basal projection of the lines of two-fold saturation. The notation used refers to this figure. The simplifications made in designing the model are that all the allotropic transformations which occur in the components tungsten, graphite, cobalt and possibly in the phase $\mathrm{W}_{2} \mathrm{C}$ are omitted, that the complications caused by the $\gamma$ phase $\mathrm{Co}_{3} \mathrm{~W}$ have not been considered, and the vapor phase of cobalt is not included. It is believed that these simplifications are justified, because the allotropic phase transformations as well as the $\gamma$ formation occur at temperatures which are outside of the range of the primary interest.

The general appearance of the diagram is determined by the very high melting points of carbon and tungsten. The liquidus surface slopes sharply toward the cobalt corner. A valley of low melting extends

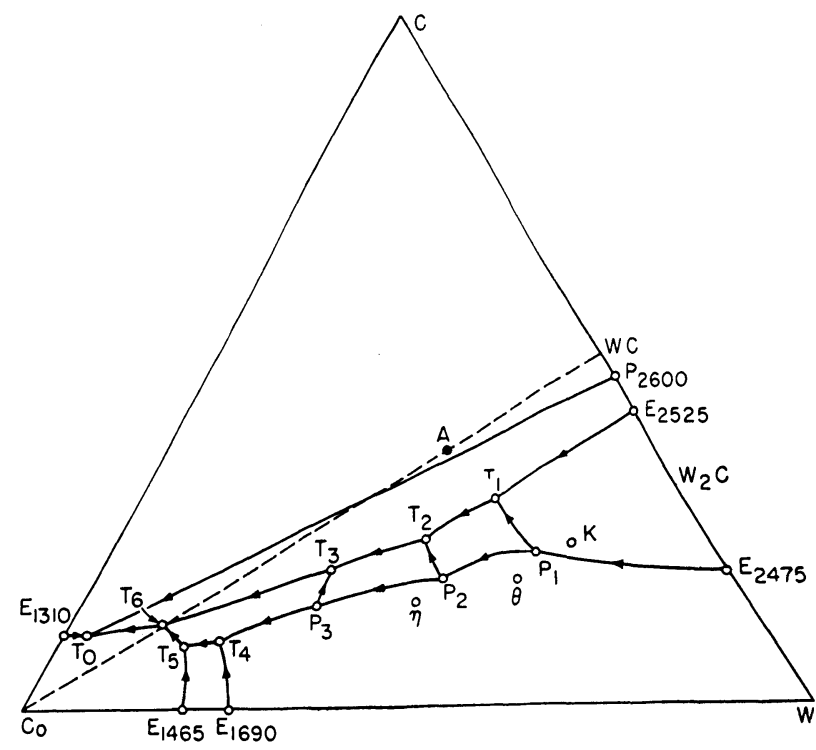

Fig. 4-Metastable equilibrium diagram W-Co-C, representation by basal projection.

$P_{1}$-Liquid $+\mathrm{W}_{2} \mathrm{C}+\mathrm{W}=\kappa \quad T_{3}$-Liquid $+\theta=\eta+\mathrm{WC}$

$T_{1}$-Liquid $+W_{2} C=\kappa+W C T_{4}$-Liquid $+W=\eta+\delta$

$P_{2}$-Liquid $+\kappa+W=\theta \quad T_{5}$-Liquid $+\delta=\beta+\eta$

$T^{2}$-Liquid $+\kappa=\theta+W C \quad T_{0}$-Liquid $+\eta=W C+\beta$

$P_{3}$-Liquid $+\theta+W=\eta \quad T_{0}$-Liquid $=W C+\beta+$ graphite 


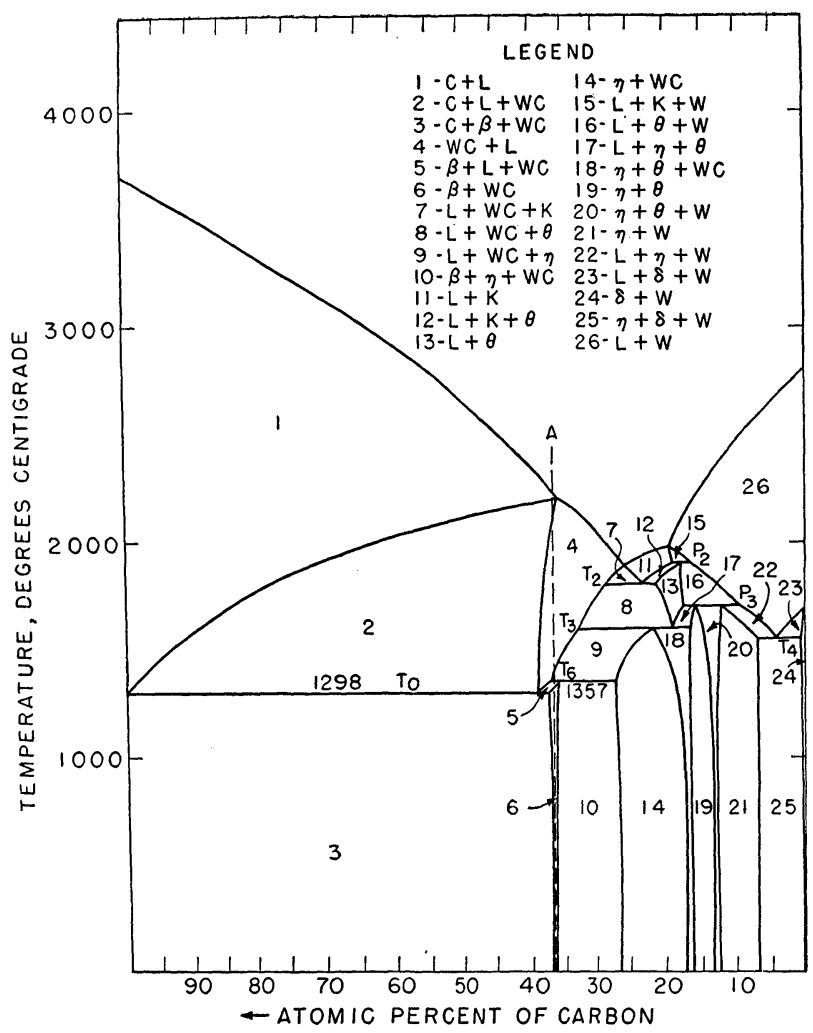

Fig. 5-Vertical section through carbon corner of metastable W.Co-C diagram. W-Co ratio is $57 / 43$. The dotted line $A$ corresponds to the composition of the cemented carbide of $18 \mathrm{wt}$ pct Co content.

from the eutectics on the W-C binary across the diagram.

The invariant temperature of the four-phase equilibrium, liquid- $\beta$-WC-graphite, was measured as $1298^{\circ} \mathrm{C}$, which was the lowest reaction temperature found. The average temperature of the lowest melt-

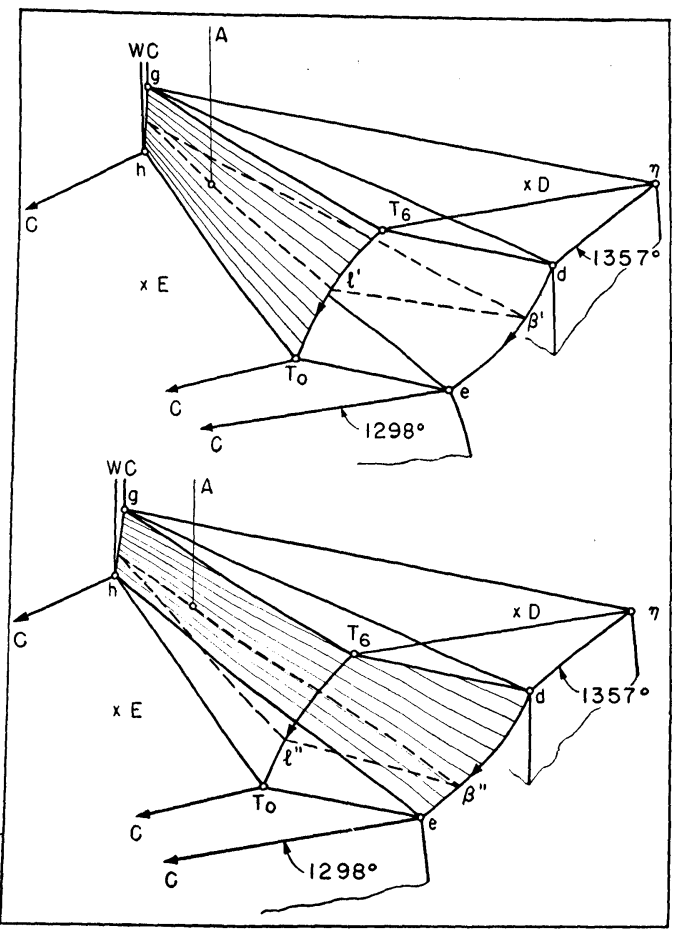

Fig. 6-Perspective illustration of solidification of cobalt cemented tungsten carbides. The composition of the alloy is given by vertical line $A$. Points $D$ and $E$ indicate the approximate compositions of the thermal analysis specimens. ing in sintering commercial two-phase alloys, $\beta+$ WC, seems to be about $1320^{\circ} \mathrm{C}^{2}$ The invariant reaction at $1298^{\circ} \mathrm{C}$ then has to be a eutectic reaction:

$$
\text { Liquid }=\beta+\mathrm{WC}+\mathrm{C}
$$

The $\kappa$ phase can be formed only by a peritectic reaction. Because no WC was found in the decomposed $\kappa$, the reaction must be:

$$
\text { Liquid }+\mathrm{W}+\mathrm{W}_{2} \mathrm{C}=\kappa
$$

The composition of the liquid, indicated by the letter $P_{1}$, is not far from the $\kappa$ composition. The reaction temperature is near $1880^{\circ} \mathrm{C}$ because of the three $\kappa$ specimens heated to $1880^{\circ} \mathrm{C}$, two decomposed and one did not. Since the accuracy of the temperature measurement in this range is about $\pm 15^{\circ} \mathrm{C}$, this means that the invariant temperature is between $1865^{\circ}$ and $1895^{\circ} \mathrm{C}$. The reaction provides the twophase equilibria $\kappa+\mathrm{W}_{2} \mathrm{C}$ and $\kappa+\mathrm{W}$, which were found at $1400^{\circ} \mathrm{C}$.

To obtain the $\kappa$-WC equilibrium, also found, a ternary transition:

$$
\text { Liquid }+\mathrm{W}_{2} \mathrm{C}=\kappa+\mathrm{WC}
$$

has to occur at somewhat lower temperature $T_{1}$.

The formation of the $\theta$ phase is similar to the $\kappa$

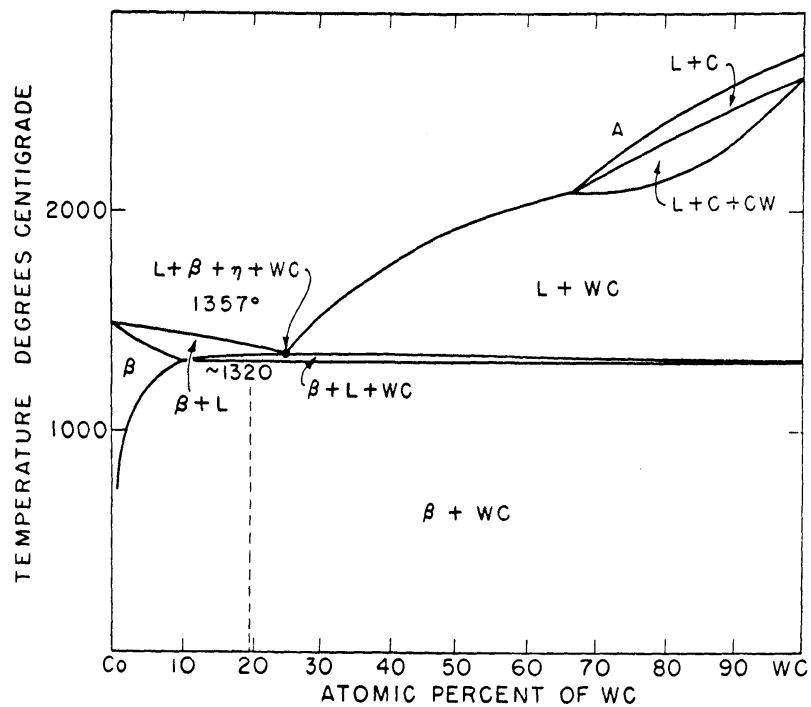

Fig. 7-Vertical section of Co-WC. Because experimental data is lacking, a special case is illustrated.

reaction, and in accordance with the experiments the peritectic reaction is:

$$
\text { Liquid }+\kappa+\mathrm{W}=\theta
$$

The reaction temperature $P_{2}$ is in the neighborhood of $1700^{\circ} \mathrm{C}$, but is not known accurately. This reaction furnishes the experimentally found twophase fields $\theta+\kappa$ and $\theta+\mathrm{W}$. The ternary transition:

$$
\text { Liquid }+\kappa=\theta+\mathrm{WC}
$$

provides the two-phase field $\theta+\mathrm{WC}$. This reaction temperature $T_{2}$ has to be lower than $P_{2}$.

There is not much experimental support for the nature of the $\eta$ reaction. The various attempts made, were upset by the evaporation of cobalt. It is believed that the temperature of the invariant reaction of the $\eta$ formation is about $1600^{\circ} \mathrm{C}$. The peritectic reaction, Liquid $+\theta+\mathrm{W}=\eta$ is considered the only possibility.

The reaction, Liquid $+\theta+\mathrm{W}=\eta$ would give the two-phase fields $\eta+\theta$ and $\eta+\mathrm{W}$, and the transition, Liquid $+\theta=\eta+\mathrm{WC}$ at a lower temperature supplies the field $\eta+\mathrm{WC}$. 


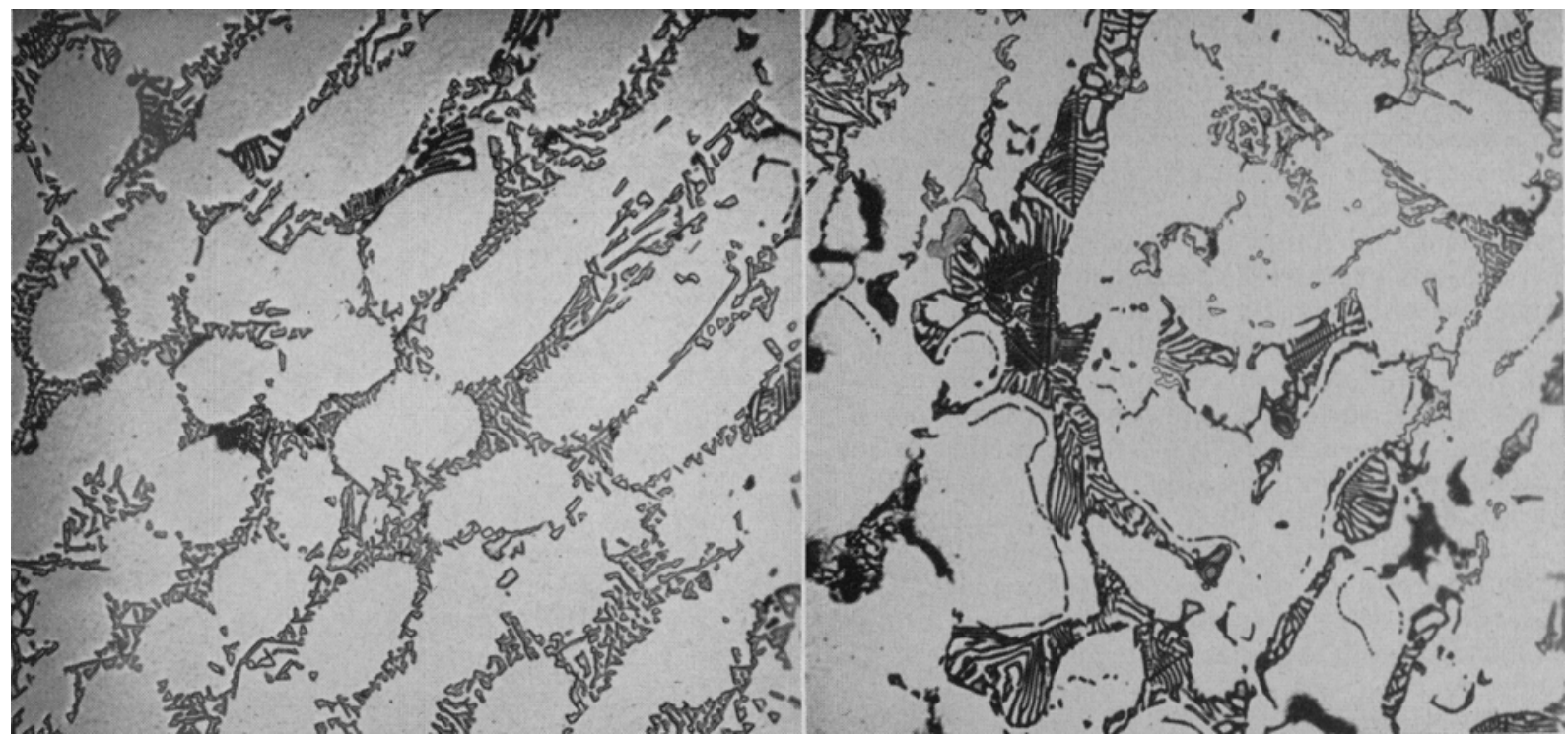

a-Cross section near surface. Primary $\beta$ and $W C+\beta$.

b-Cross section in core. Primary $\beta, \eta+\beta$ and graphite.

Fig. 8-Microstructure of 9 pct W-81 pct Co-10 pet $C$ alloy. Etched by alkaline $\mathrm{K}_{3} \mathrm{Fe}(\mathrm{CN})_{6}$. X250.

The experimentally verified $\eta-\delta$ field is a product of ternary transition, Liquid $+\mathrm{W}=\eta+\delta$. The $\eta$ - $\beta$ equilibrium, which exists at $1400^{\circ} \mathrm{C}$ and below, is formed by a ternary transition, Liquid $+\delta=$ $\eta+\beta$. At $1357^{\circ} \mathrm{C}$ a ternary transition reaction, Liquid $+\eta=\beta+\mathrm{WC}$, forms the important twophase equilibrium $\beta$-WC.

Not much has been said as to the compositions of the reacting phases. This is especially true with the compositions of the saturated liquids. The solid phase compositions are, in general, well fixed. It has been revealed in this study that the homogeneity ranges of all participating phases are very narrow. The only exception is the $\eta$ phase.

It is possible to locate the ternary eutectic to within a few percentage points by pure speculation. The ternary eutectic temperature was measured as $1298^{\circ} \mathrm{C}$. The binary eutectic reaction, Liquid $=\beta$ $+\mathrm{C}$ has been reported between $1300^{\circ}$ and $1315^{\circ} \mathrm{C}$. The difference is very small, as a matter of fact within the experimental errors. It is unlikely that the ternary eutectic composition would be far from the Co-C binary. But on the other hand, there is cumulative evidence that the maximum solubility of WC in cobalt is about 10 pct. Yet the eutectic point has to be within the three-phase field corner and not far from the section Co-WC because toward the carbon corner the liquidus surface is almost vertical.

One point of great practical importance is the composition of the liquid phase in the reaction: Liquid $+\eta=\beta+$ WC. Fig. 5 represents a vertical section through the carbon corner of the diagram for constant W-Co ratio of $57 / 43$. This is a section which includes cemented carbides of 18 wt pct Co content. An alloy of this composition, which at low temperatures would have a two-phase $\beta+$ WC structure, is represented by line $A$. It is evident that the extension of the invariant plane at $1357^{\circ} \mathrm{C}$ will determine whether or not $\eta$ phase is formed during heating or cooling of the specimens. The question is important because it will form the basis of understanding the sintering mechanism of the cemented carbides.

The reactions occurring during cooling from the sintering temperature can be followed by Fig. 6 . The common sintering temperature is about $1400^{\circ} \mathrm{C}$. The specimen at this temperature consists of solid WC and liquid. During cooling WC precipitates, and the composition of the liquid follows the surface of onefold saturation until the line $T_{6}-T_{0}$ is encountered. During further cooling, WC and $\beta$ precipitate simultaneously. The composition of the precipitating $\beta$ follows the curve $d-e$. When the line WC- $\beta$ intersects the vertical $A$, all liquid has been consumed and solidification is complete. Depending on the cooling rate, various amounts of WC will precipitate out of the $\beta$ solid solution during subsequent cooling to room temperature.

If the invariant plane $g-T_{6}-d-\eta$ extends completely over the two-phase field WC $+\beta$, the two-fold precipitation will be $\mathrm{WC}+\eta$ until the invariant temperature is reached.

The vertical section, Co-WC is illustrated in Fig. 7. Because it is not known whether or not the $1357^{\circ} \mathrm{C}$ invariant plane extends over the two-phase field, $\beta+\mathrm{WC}$, a compromise has been made by drawing a special case represented by a point at $1357^{\circ} \mathrm{C}$. If the carbon content of the saturated liquid at $1357^{\circ} \mathrm{C}$ is higher than indicated, two three-phase fields and one two-phase field will be generated from the point at $1357^{\circ} \mathrm{C}$. In the opposite case the four-phase equilibrium will disappear.

\section{Instability of Carbides}

The instability of $\eta$ phase has been reported by Takeda ${ }^{4}$ in the Fe-W-C system. The basis of Takeda's hypothesis seems to be a micrograph of an annealed $\eta$ grain, which according to Takeda, shows a rim of WC formed by decomposition of $\eta$. However, it is believed here that the rim was nothing but $\eta$, from which a heavy layer of etching stain had been chipped off. If a more careful etching technique would have been applied, probably no such rim would have been visible. Takeda's instability hypothesis was accepted by Westgren. ${ }^{1}$ To verify it, Westgren annealed a specimen of composition $\mathrm{Ni}_{3} \mathrm{~W}_{3} \mathrm{C}$ for ten days at $1000^{\circ} \mathrm{C}$ and the result was WC. It is believed here that carburization took place in this experiment. It will be shown by the following experiment that the $\eta$ phase is stable.

A specimen of composition 81.0 pct $\mathrm{Co}, 9.0$ pct W, and 10.0 pct $\mathrm{C}$ was heated to $1500^{\circ} \mathrm{C}$ in an alundum crucible by induction. At $1500^{\circ} \mathrm{C}$ the alloy was ex- 
pected to consist of liquid phase only. The specimen was then furnace cooled. A section through the solidified specimens showed two types of structures. The surface layer, shown in Fig. 8a, consists of primary $\beta$ surrounded by a fine structure of $\beta$ and WC. The center of the specimen, shown in Fig. 8b, also shows primary $\beta$ but now surrounded by $\eta-\beta$ eutectic and numerous graphite flakes. The condition in the furnace was only slightly carburizing, if at all. The alundum crucible was enclosed in a graphite crucible, which was completely packed in norblack. The cooling rate on the surface of the specimen is expected to be faster than inside. The surface structure is in accordance with the metastable diagram. During the cooling from the liquid state the precipitation of $\beta$ starts first and during subsequent cooling simultaneous precipitation of $\mathrm{WC}$ and $\beta$ takes place. The composition of the specimen is such that all liquid is consumed before the eutectic temperature $1298^{\circ} \mathrm{C}$ has been reached.

The structure of the specimen core, apparently cooled slower, cannot be explained by means of the metastable diagram, which has no $\eta$-graphite equilibrium. Apparently the core has approached true equilibrium conditions more closely and thus the combination $\mathrm{C}_{0}-\eta$-graphite is the stable one. It will be noted that the composition of the specimen was not changed. The free graphite amounts to the difference between the carbon contents of WC and $\eta$.

\section{Tentative Model of Stable Diagram W-Co-C}

A stable system may be developed from the metastable by omitting the ternary transition at $1357^{\circ} \mathrm{C}$. Above this temperature the stable and the metastable diagrams are essentially the same. In the stable system the ternary transition:

$$
\text { Liquid }+\mathrm{WC}=\eta+\mathrm{C}
$$

produces the $\eta$-graphite equilibrium.

At a lower temperature a eutectic reaction:

$$
\text { Liquid }=\beta+\eta+\mathrm{C}
$$

produces the three phase field $\beta-\eta$-graphite. $\dagger$

$\dagger$ The temperature of this eutectic reaction was not revealed by the thermal analyses described. Apparently the thermocouple promen so that no $n$ phase was formed from the center of the speciperature of the eutectic reaction in the stable system is lower than in the metastable system.

A model of the stable equilibrium diagram $\mathrm{W}-\mathrm{Co}-$ $\mathrm{C}$ is illustrated in Fig. 9.

The characteristic feature of the metastable diagram is the two-phase field $\beta$-WC, which extends across the diagram. The cemented carbides should

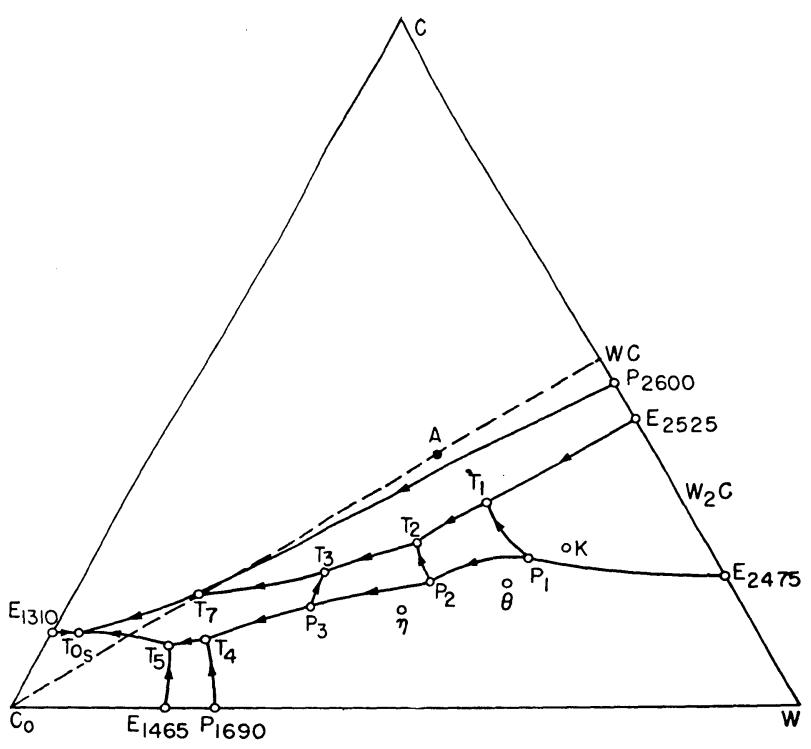

Fig. 9-Stable equilibrium diagram of W-Co-C. Representation by basal projection. The reactions $P_{1}$ to $T_{5}$ are the same as in Fig. 4. $T_{7}$ - Liquid $+W C=\eta+$ graphite. $T_{0_{s}}$-Liquid $=\beta+\eta+$ graphite.

have this structure. In the stable system this important two-phase equilibrium is destroyed. From the viewpoint of technical applications it is clear that the stable equilibrium is most undesirable. Therefore slow cooling rates from the sintering temperatures must be avoided.

\section{Acknowledgment}

Part of this work was sponsored by the Ordnance Dept. of the United States Army, Contracts No. W19-020-ORD-6489 and No. DA-19-020-ORD-10, under the technical supervision of the Watertown Arsenal Laboratory. Permission to publish the results is gratefully acknowledged.

\section{References}

${ }^{1}$ V. Adelskold, A. Sundelin, and A. Westgren: Ztsch. anorg. allgem. Chem. (1933) 212, p. 401.

${ }^{2}$ E. J. Sandford and E. M. Trent: Symposium on Powder Metallurgy. Iron and Steel Inst. Special Report 38, (1947) p. 84.

${ }^{\mathbf{3}}$ E. N. Kislyokova: Zhur, Fiz. Khim. (1943) 17, p. 108.

${ }^{4}$ S. Takeda: Technol. Repts. Tohoku Imp. Univ. (1931) 9, pp. 483, 627; and (1931) 10, p. 42.

${ }^{5}$ L. L. Wyman and F. C. Kelley: Trans. AIME (1931) 93, p. 208.

${ }^{6}$ A. Westgren: Jernkontorets Ann. (1933) 11\%, p. 1.

${ }^{7}$ L. D. Brownlee: Unpublished Report, Vickers Electrical Co. Ltd., Manchester, England.

\section{Technical Note Strain Sensitivity of Commercial Purity Titanium}

\section{by James L. Wyatt}

$\mathrm{T}$ HE strain sensitivity, $K$, a property of metals defined as the unit change in electrical resistance per unit strain, was measured for commercial purity titanium wire to determine its usefulness as a strain gage material. A Kelvin double bridge, accurate to $0.000001 \mathrm{ohm}$, was used to make measurements from 0 to 1 pct total strain. A positive

J. L. WYATT, Junior Member AIME, is National Lead Co. Fellow, Massachusetts Institute of Technology, Cambridge, Mass. TN 128E. Manuscript, April 29, 1952; revised, Aug. 5, 1952. value of 0.17 for $K$ was found. This compares with 2.15 for constantan and 3.5 for cold-worked invar, two of the more common strain gage materials.

The effect of temperature also was determined. It was found that a change in temperature of $30^{\circ} \mathrm{F}$ caused the same resistance change as 1 pct strain. It is therefore concluded that titanium would have utility as a strain gage only if the thermal fluctuations in the specimen could be controlled to a high degree and in applications of very large total strain. 